\title{
CD20 and CD37 antibodies synergize to activate complement by Fc-mediated clustering
}

\author{
Simone C. Oostindie, ${ }^{1,2}$ Hilma J. van der Horst, ${ }^{3}$ Margaret A. Lindorfer, ${ }^{4}$ \\ Erika M. Cook, ${ }^{4}$ Jillian C. Tupitza, ${ }^{4}$ Clive S. Zent, ${ }^{5}$ Richard Burack, ${ }^{5}$ \\ Karl R. VanDerMeid, ${ }^{5}$ Kristin Strumane, ${ }^{1}$ Martine E. D. Chamuleau, ${ }^{3}$ \\ Tuna Mutis, ${ }^{3}$ Rob N. de Jong, ${ }^{1}$ Janine Schuurman, ${ }^{1}$ Esther C. W. Breij, ${ }^{1}$ \\ Frank J. Beurskens, ${ }^{1}$ Paul W. H. I. Parren ${ }^{2,6}$ and Ronald P. Taylor ${ }^{4}$
}

${ }^{1}$ Genmab, Utrecht, the Netherlands; ${ }^{2}$ Department of Immunohematology and Blood Transfusion, Leiden University Medical Center, Leiden, the Netherlands; ${ }^{3}$ Department of Hematology, Amsterdam University Medical Center, Amsterdam, the Netherlands; ${ }^{4}$ Department of Biochemistry and Molecular Genetics, University of Virginia School of Medicine, Charlottesville, Virginia, USA; ${ }^{5}$ Wilmot Cancer Institute, University of Rochester Medical Center, Rochester, NY, USA and ' $L a v a$ Therapeutics, Utrecht, the Netherlands

\section{ABSTRAGT}

C D20 monoclonal antibody therapies have significantly improved the outlook for patients with B-cell malignancies. However, many patients acquire resistance, demonstrating the need for new and improved drugs. We previously demonstrated that the natural process of antibody hexamer formation on targeted cells allows for optimal induction of complement-dependent cytotoxicity. Complement-dependent cytotoxicity can be potentiated by introducing a single point mutation such as E430G in the IgG Fc domain that enhances intermolecular Fc-Fc interactions between cell-bound IgG molecules, thereby facilitating IgG hexamer formation. Antibodies specific for CD37, a target that is abundantly expressed on healthy and malignant B cells, are generally poor inducers of complement-dependent cytotoxicity. Here we demonstrate that introduction of the hexamerization-enhancing mutation E430G in CD37-specific antibodies facilitates highly potent complement-dependent cytotoxicity in chronic lymphocytic leukemia cells ex vivo. Strikingly, we observed that combinations of hexamerization-enhanced CD20 and CD37 antibodies cooperated in C1q binding and induced superior and synergistic complement-dependent cytotoxicity in patient-derived cancer cells compared to the single agents. Furthermore, CD20 and CD37 antibodies colocalized on the cell membrane, an effect that was potentiated by the hexamerization-enhancing mutation. Moreover, upon cell surface binding, CD20 and CD37 antibodies were shown to form mixed hexameric antibody complexes consisting of both antibodies each bound to their own cognate target, so-called hetero-hexamers. These findings provide novel insights into the mechanisms of synergy in antibody-mediated complement-dependent cytotoxicity and provide a rationale to explore Fc-engineering and antibody hetero-hexamerization as a tool to enhance the cooperativity and therapeutic efficacy of antibody combinations.

\section{Introduction}

Monoclonal antibodies ( $\mathrm{mAbS}$ ) have become the backbone of treatment regimens for several cancer indications. The chimeric immunoglobulin (Ig)G1 CD20 mAb rituximab was the first $\mathrm{mAb}$ approved for clinical use in cancer therapy. CD20 is expressed on more than $90 \%$ of mature B cells and rituximab is widely used to treat B-cell malignancies. ${ }^{1-3}$ However, many patients do not experience complete remission or acquire resistance to rituximab treatment, thereby demonstrating the need for improved $\mathrm{mAb}$ therapeutics or alternative tumor-targeting strategies..$^{4-6}$
Ferrata Storti Foundation
Haematologica 2019

Volume 104(9):1841-1852

\section{Correspondence:}

SIMONE C. OOSTINDIE

sio@genmab.com

RONALD P. TAYLOR

rpt@virginia.edu

Received: October 2, 2018.

Accepted: February 19, 2019.

Pre-published: February 21, 2019.

doi:10.3324/haematol.2018.207266

Check the online version for the most updated information on this article, online supplements, and information on authorship \& disclosures: www.haematologica.org/content/104/9/1841

(C)2019 Ferrata Storti Foundation

Material published in Haematologica is covered by copyright. All rights are reserved to the Ferrata Storti Foundation. Use of published material is allowed under the following terms and conditions:

https://creativecommons.org/licenses/by-nc/4.0/legalcode. Copies of published material are allowed for personal or internal use. Sharing published material for non-commercial purposes is subject to the following conditions: https://creativecommons.org/licenses/by-nc/4.0/legalcode, sect. 3. Reproducing and sharing published material for commercial purposes is not allowed without permission in writing from the publisher. 
mAbs employ various mechanisms to eliminate cancer cells, such as induction of programmed cell death or Fcmediated effector functions, including antibody-dependent cell-mediated cytotoxicity (ADCC), antibody-dependent cellular phagocytosis (ADCP), and complementdependent cytotoxicity (CDC), which can be increased by Fc engineering. ADCC and ADCP, for example, can be enhanced by improving Fc $\gamma$ R binding through Fc glycoengineering or amino acid modifications. ${ }^{8-11}$ Likewise, C1q binding and CDC can be increased by amino acid substitutions in Fc domains. ${ }^{12,13} \mathrm{CDC}$ is initiated when membrane-bound antibodies bind the hexavalent C1q molecule, which together with C1r and C1s forms the C1 complex, the first component of the classical complement pathway. C1 activation triggers an enzymatic cascade that leads to covalent attachment of opsonins to target cells, and the generation of potent chemoattractants, anaphylatoxins and membrane attack complexes (MAC). ${ }^{14}$ IgG antibodies bound to cell surface antigens assemble into ordered hexamers, providing high avidity docking sites to which $\mathrm{C} 1$ binds and is activated. ${ }^{15}$ IgG hexamer formation and complement activation can be enhanced by single point mutations in IgG Fc domains, such as E430G, which increase interactions between Fc domains of cell-bound IgG. ${ }^{16}$ The hexamerization-enhanced (Hx) CD20-targeting $\mathrm{mAb} 7 \mathrm{D} 8$ displayed strongly enhanced CDC of B cells from patients with chronic lymphocytic leukemia (CLL), which often demonstrate complement resistance due to low CD20 and high membrane complement regulatory protein (mCRP) expression. ${ }^{16-18}$

In polyclonal antibody responses, antibodies against distinct epitopes or antigens are thought to cooperate resulting in increased effector functions against target cells. This increase can be mimicked in mAb combinations or cocktails. For example, mAbs targeting epidermal growth factor receptor (EGFR) do not induce CDC in vitro, but combinations of $\mathrm{mAbs}$ against multiple EGFR epitopes induced potent CDC. ${ }^{19,20}$

CD37, which is abundantly expressed on B cells, represents a promising therapeutic target for the treatment of $\mathrm{B}$ cell malignancies. ${ }^{21,22}$ Currently known CD37 mAbs in clinical development, however, are generally poor inducers of CDC. ${ }^{23-27}$ Here we show that introducing Hx mutations into CD37 mAbs strongly potentiated CDC of CLL cells, and that combinations of CD20 and CD37 targeting mAbs could further enhance CDC of tumor cell lines and primary patient cells. We investigated the mechanism behind the synergistic CDC activity of CD20 and CD37 mAbs, and found that the $\mathrm{mAb}$ combinations activate complement cooperatively. The two mAbs formed mixed hexameric antibody complexes consisting of both antibodies each bound to their cognate targets, which we termed heterohexamers. The concept of hetero-hexamer formation and the use of Fc-Fc interaction enhancing mutations could serve as a tool to enhance cooperativity, and thereby the tumor killing capacity, of $\mathrm{mAb}$ combinations.

\section{Methods}

\section{Cells}

Daudi, Raji and WIL2-S B-lymphoma cell lines were obtained from the American Type Culture Collection (ATCC n. CCL-213, CCL-86 and CRL-8885, respectively). All primary patient cells used in this study were obtained after written and informed consent and stored using protocols approved by the institutional review boards in accordance with the Declaration of Helsinki (Online Supplementary Methods).

\section{Antibodies and reagents}

mAb IgG1-CD20-7D8, IgG1-CD20-11B8, IgG1-CD37 clone 37.3 and IgG1-gp120 were recombinantly produced at Genmab. ${ }^{18,28-30}$ The HIV-1 gp120 mAb b12 was used to determine assay background signal. Mutations to enhance or inhibit Fc-Fc interactions were introduced in expression vectors encoding the antibody heavy chain by gene synthesis (GeneArt). Rituximab (MabThera ${ }^{\circledR}$ ), ofatumumab (Arzerra ${ }^{\circledR}$ ), and obinutuzumab (Gazyvaroß) were obtained from the institutional pharmacy (UMC Utrecht). See Online Supplementary Methods for details on reagents used.

\section{CDC assays}

CDC assays with CLL patient cells were performed with human complement as described. ${ }^{31}$ CDC assays with B-lymphoma cell lines and patient-derived B-lymphoma cells were per-formed using 100,000 target cells incubated [ 45 minutes $(\mathrm{min})$ at $37^{\circ} \mathrm{C}$ ] with a $\mathrm{mAb}$ concentration series and pooled normal human serum (NHS, $20 \%$ final concentration) as a complement source. Killing was calculated as the percentage of propidium idodide (PI) or 7-AAD positive cells determined by flow cytometry. See Online Supplementary Methods for details on cell markers used to define cell populations.

\section{Expression analysis}

Expression levels of cellular markers were determined using an indirect immunofluorescence assay (OIFIKIT®, BioCytex) according to the manufacturer's instructions (Online Supplementary Methods).

\section{C1q binding and CDC efficacy}

Daudi cells $\left(3 \times 10^{6}\right.$ cells $\left./ \mathrm{mL}\right)$ were incubated with $10 \mu \mathrm{g} / \mathrm{mL}$ $\mathrm{mAb}$ and a concentration series of purified human $\mathrm{C} 1 \mathrm{q}$ for $45 \mathrm{~min}$ at $37^{\circ} \mathrm{C}$. After washing, cells were incubated with FITC-labeled rabbit anti-human C1q antibody for $30 \mathrm{~min}$ at $4^{\circ} \mathrm{C}$ and analyzed on a FACS Canto II flow cytometer (BD Biosciences, CA, USA). The efficiency of $\mathrm{C} 1 \mathrm{q}$ binding and subsequent $\mathrm{CDC}$ was assessed as described above using fixed $\mathrm{mAb}$ concentrations, a concentration series of purified C1q and 20\% C1q depleted serum.

\section{Confocal microscopy}

Raji cells were opsonized with A488 labeled Hx-CD20-7D8 and A594 labeled Hx-CD37 mAbs (2.5 $\mu \mathrm{g} / \mathrm{mL}$ final concentrations), and incubated for $15 \mathrm{~min}$ at room temperature. After washing, cells were placed on a poly-D lysine-coated slide and images were captured with a Zeiss AxioObserver LSM 700 microscope using plan-Apochromat 63X/1.40 Oil DIC M27 objective lenses and acquired/processed using Zen software.

\section{Förster resonance energy transfer analysis}

Proximity-induced Förster resonance energy transfer (FRET) analysis was determined by measuring energy transfer between cells incubated with A555-conjugated donor and A647-conjugated acceptor mAbs using flow cytometry (Online Supplementary Methods). The dynamic range of FRET analysis by flow cytometry was determined using control mAbs (Online Supplementary Figure S1).

\section{Data processing and statistical analyses}

All values are expressed as the mean \pm Standard Deviation of at least two independent experiments. Graphs were generated and analyzed using GraphPad Prism 7.0 (CA, USA). Differences 
between two groups were analyzed using paired Student $t$-test with two-tailed 95\% Confidence Intervals and between more groups by paired or unpaired one-way ANOVA followed by a Tukey's post-hoc multiple comparisons test. See Online Supplementary Methods for details on synergy and colocalization analysis.

\section{Results}

\section{Hexamerization-enhancing mutations in CD20 and CD37 mAbs substantially enhance complement-dependent cytotoxicity of chronic lymphocytic leukemia B cells}

We previously reported increased CDC with engineered $\mathrm{mAbs}$ containing Hx mutations in the Fc domain. ${ }^{15,16} \mathrm{We}$ therefore investigated whether introducing the $\mathrm{Hx}$ mutation E430G into the CD37 chimeric IgG1 mAb 37.3 could potentiate CDC in B cells isolated from chronic lymphocytic leukemia (CLL) patients and compared this to the CD20 mAb IgG1-CD20-7D8 with and without a Hx mutation. Wild-type (WT) IgG1-CD20-7D8 promoted considerable CDC of CLL B cells and CDC was increased by the E430G mutation (Figure 1A). While WT IgG1-CD37 efficiently binds to CLL B cells, it was ineffective at inducing CDC (Figure $1 \mathrm{~B}$ and Online Supplementary Figure S2), in contrast to Hx-CD37 (Figure 1B). For both Hx-CD20-7D8 and Hx-CD37, high levels of cell killing largely required active complement, since $\mathrm{CDC}$ was almost absent in heat-inactivated NHS, NHS supplemented with EDTA or medium alone (Figure 1A and B). Background killing of cells from patient A mediated by Hx-CD37 in the absence of complement, was slightly higher than expected. However, in C1q-depleted serum, background killing was $16 \%$, compared to $6 \%$ for cells reacted with Hx-CD20-7D8. Background killing in C1qdepleted serum for six other CLL patient samples averaged $13 \%$ and $14 \%$ for cells reacted with $\mathrm{Hx}-\mathrm{CD} 20-7 \mathrm{D} 8$ and $\mathrm{Hx}-\mathrm{CD} 37$, respectively. Reaction in NHS increased CDC to averages of $91 \%$ and $95 \%$, respectively. Introduction of the Hx mutation E430G into CD20 and CD37 mAbs did not affect pharmacokinetic profiles and binding to FcRn (data not shown). ${ }^{16}$ At the highest concentration $(16 \mu \mathrm{g} / \mathrm{mL}) \mathrm{Hx}-\mathrm{CD} 37$ induced $\geq 95 \%$ CDC of tumor B cells for 9 of 12 patients (Figure 1C). At concentrations of 0.25 and $2 \mu \mathrm{g} / \mathrm{mL}$, Hx-CD37 generally demonstrated higher potency than Hx-CD20-7D8 (Figure 1D and E), which may be explained by higher expression levels of CD37 (approximately 2-fold) in the majority of CLL samples (Online Supplementary Figure S3A and B).

\section{CD20 and CD37 mAbs synergistically induce complement-dependent cytotoxicity of malignant B cells}

We investigated the CDC activity of combinations of WT CD20 and WT CD37 mAbs using two different CD20 mAbs. The ability to activate complement represents a key distinction between type I CD20 mAbs, which mediate strong CDC, and type II CD20 mAbs, which only mediate weak $\mathrm{CDC}^{32}$ The effect of combining WT type I CD20 mAb 7D8 or WT type II CD20 mAb 11B8 with WT CD37 mAbs on CDC was assessed using Daudi cells. As expected, WT IgG1-CD20-7D8 showed potent CDC activity $(96.6 \%$ cell lysis), whereas WT IgG1-CD37 did not induce CDC (Figure 2A). The combination of WT
IgG1-CD20-7D8 and WT IgG1-CD37 did not demonstrate enhanced CDC. However, while neither WT IgG1CD20-11B8 nor WT IgG1-CD37 induced CDC as single agents, the combination promoted strong lysis of approximately $60 \%$ (Figure 2B). Minimal cell lysis was observed in experiments with heat-inactivated serum, indicating that that cell killing was largely dependent on complement (Online Supplementary Figure S4).

We also examined whether combinations of CD20 and CD37 mAbs with $\mathrm{Hx}$ mutations also showed cooperativity in $\mathrm{CDC}$ by testing $\mathrm{mAb}$ combinations using a full dose-response matrix (8x8 serial dilution grid) based on the EC50 values of the different mAbs. Surprisingly, both Hx-CD20-7D8 and Hx-CD20-11B8 in combination with $\mathrm{Hx}-\mathrm{CD} 37$ showed enhanced CDC of Daudi cells compared to the single agents (Figure 2C and Online Supplementary Figure S5A). We next assessed whether the observed combination effect was synergistic using the Loewe additivity-based combination index (CI) score calculated by CompuSyn, whereby effects were categorized as synergistic $(\mathrm{CI}<1)$, additive $(\mathrm{CI}=1)$, or antagonistic $(\mathrm{CI}>1){ }^{33}$ The Loewe additivity-based model assumes synergy when the effect of a drug combination is higher than the effect of a drug combined with itself, and takes into account both the potency and the shape of the dose-effect curve of each drug in the dose-response matrix. Synergy was observed for both Hx-CD20-7D8 and Hx-CD20-11B8 when combined with $\mathrm{Hx}$-CD37, with average $\mathrm{CI}$ values of 0.37 and 0.31 (effective dose - ED95), respectively (Figure 2D, Online Supplementary Table S1 and Online Supplementary Figure S5B). At the lower tested mAb concentrations, synergy was more profound (lower $\mathrm{CI}$ values) for combinations of $\mathrm{Hx}-\mathrm{CD} 37$ with type II CD20 mAbderived $\mathrm{Hx}-\mathrm{CD} 20-11 \mathrm{~B} 8$ than with type I CD20 mAbderived Hx-CD20-7D8.

In addition to Daudi cells, we used two other B-cell lines expressing various levels of CD20 and CD37 to further examine the cooperativity in $\mathrm{CDC}$ between combinations of $\mathrm{Hx}$-CD37 with $\mathrm{Hx}-\mathrm{CD} 20 \mathrm{mAbs}$ or with clinically validated CD20 mAbs. Across all B-cell lines tested, enhanced CDC activity was observed for combinations of $\mathrm{Hx}-\mathrm{CD} 37$ with $\mathrm{Hx}$-CD20 mAbs, as well as for combinations of $\mathrm{Hx}$ CD37 with ofatumumab, rituximab and obinutuzumab (Figure 2E). Even in WIL2-S cells expressing low levels of CD37, a combination of Hx-CD37 with obinutuzumab induced $72 \%$ lysis, whereas the single agents induced only $5 \%$ and $10 \%$ lysis respectively. Despite high single agent activity of $\mathrm{Hx}-\mathrm{CD} 37$ and $\mathrm{Hx}-\mathrm{CD} 20 \mathrm{mAbs}$ at $10 \mu \mathrm{g} / \mathrm{mL}$ (per $\mathrm{mAb}$ ) in Daudi cells, the cooperativity between $\mathrm{Hx}$ CD37 and Hx-CD20 mAbs became apparent at the lower $\mathrm{mAb}$ concentrations.

\section{Enhanced binding and use of $\mathrm{C} 1 \mathrm{q}$ by combinations of hexamerization-enhanced CD20 and CD37 mAbs}

We hypothesized that the observed synergy in CDC between Hx-CD20 and Hx-CD37 mAbs resulted from more efficient use of complement proteins, starting with binding of C1q. Therefore, we determined whether combinations of $\mathrm{Hx}-\mathrm{CD} 20$ and $\mathrm{Hx}-\mathrm{CD} 37$ differed in their $\mathrm{C} 1 \mathrm{q}$ binding capacity. We incubated Daudi cells with fixed $\mathrm{mAb}$ concentrations and titrated $\mathrm{C} 1 \mathrm{q}$, and measured $\mathrm{C} 1 \mathrm{q}$ binding and the concentration of $\mathrm{C} 1 \mathrm{q}$ required to induce CDC, referred to here as CDC efficacy. Hx-CD20-7D8 already induced efficient $\mathrm{C} 1 \mathrm{q}$ binding as a single agent, while Hx-CD37 showed limited C1q binding (Figure 3A). 
Combinations of $\mathrm{Hx}-\mathrm{CD} 20-7 \mathrm{D} 8$ and $\mathrm{Hx}-\mathrm{CD} 37$ did not significantly increase $\mathrm{C} 1 \mathrm{q}$ binding. However, the combination showed higher CDC efficacy as demonstrated by the lower EC50 value in the $\mathrm{C1q}$ dose-response curves compared to the single mAbs $(0.03 \mu \mathrm{g} / \mathrm{mL}$ for the combination vs. $0.12 \mu \mathrm{g} / \mathrm{mL}$ for Hx-CD20-7D8 and $0.34 \mu \mathrm{g} / \mathrm{mL}$ for $\mathrm{Hx}-\mathrm{CD} 20-11 \mathrm{~B} 8$ ) (Figure $3 \mathrm{~B}$ ). In contrast to the results with the type I CD20 mAb-derived variant, combining type II CD20 mAb-derived Hx-CD20-11B8 with Hx$\mathrm{CD} 37$ resulted in increased $\mathrm{C} 1 \mathrm{q}$ binding compared to the single mAbs, as well as increased CDC efficacy (Figure 3C and D). Collectively, these data suggest that combinations of both type I and type II CD20 mAb-derived Hx-CD20 $\mathrm{mAb}$ with $\mathrm{Hx}-\mathrm{CD} 37 \mathrm{mAbs}$ activate complement more effectively.
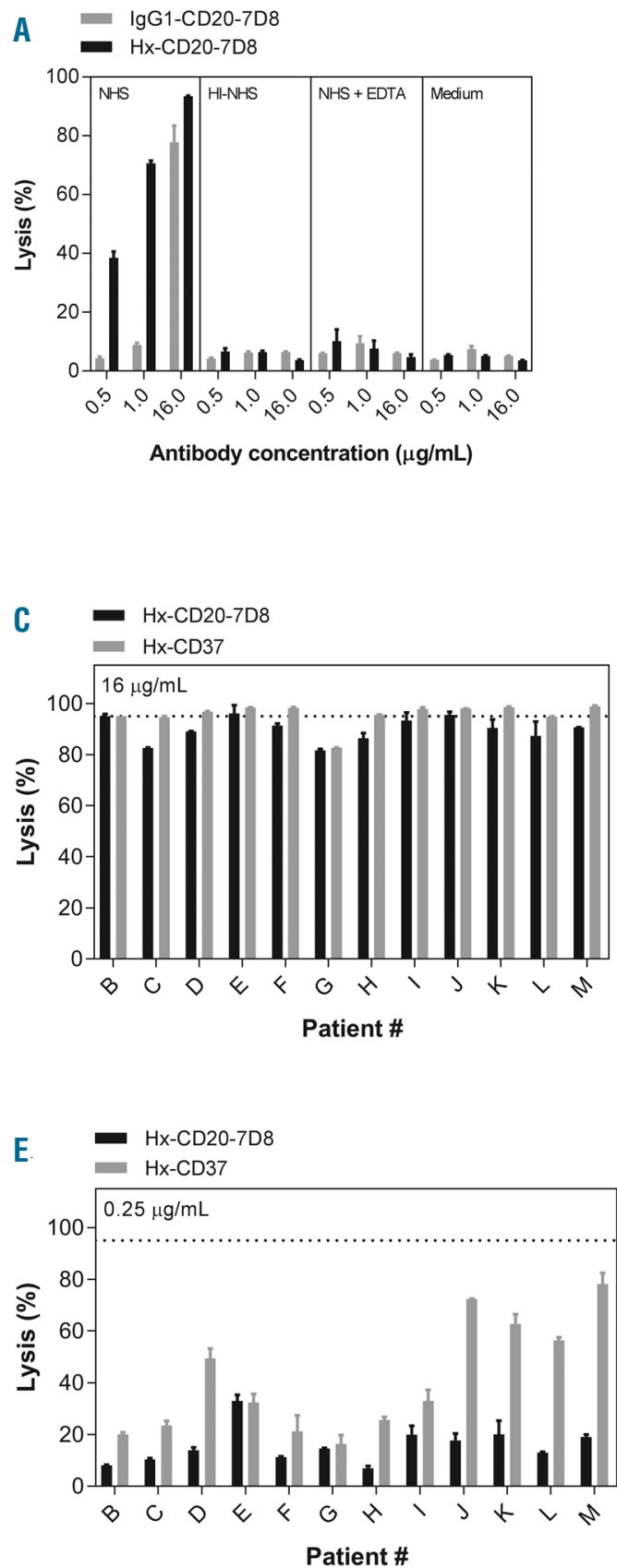

\section{CD20 and CD37 mAbs colocalize on B cells}

Confocal microscopy was used to determine whether the CD20- and CD37-specific antibodies associate on the cell surface upon target binding. Cell-bound $\mathrm{Hx}$ variants of CD20 mAb 7D8 and CD37 mAb 37.3 were detected using A488 and A594 fluorescent labeling, respectively, and antibody colocalization was quantified by calculating spatial overlap (Manders' co-efficients) between the two fluorescent labels. The merged A488/A594 image showed that membrane-bound $\mathrm{Hx}-\mathrm{CD} 20$ and $\mathrm{Hx}-\mathrm{CD} 37 \mathrm{mAbs}$ indeed colocalized on the surface of Raji cells (Figure 4A), which was confirmed by quantitative analysis, giving Manders' coefficients of $\mathrm{M} 1=0.805$ (fraction of image 1 overlapping image 2) and $M 2=0.751$ (fraction of image 2 overlapping image 1).

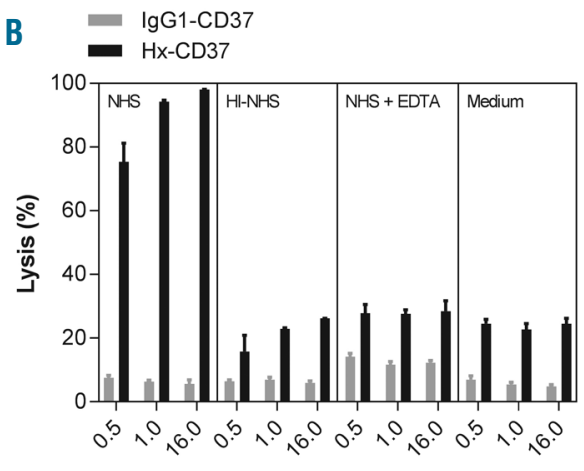

Antibody concentration $(\mu \mathrm{g} / \mathrm{mL})$

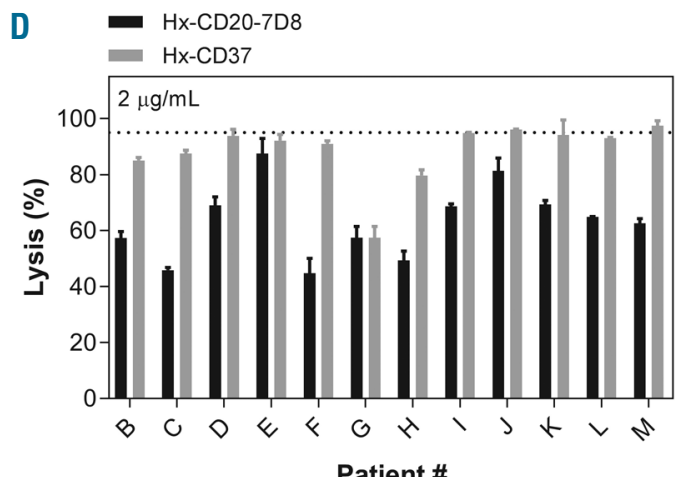

Figure 1. Hexamerization-enhancing mutations in CD20 and CD37 mAbs substantially enhance complement-dependent cytotoxicity (CDC) of chronic lymphocytic leukemia (CLL) B cells. (A and B) CDC of B cells obtained from patient A with CLL. Cells were opsonized with different concentrations of CD2O mAb 7D8 as wild type (IgG1-CD20-7D8) or with a hexamerization-enhancing mutation (Hx-CD20-7D8) (A); or CD37 mAb 37.3 as wild type (IgG1-CD37) or with a hexamerization-enhancing mutation ( $\mathrm{Hx}-\mathrm{CD} 37)(\mathrm{B})$ in the presence of $50 \%$ pooled normal human serum (NHS), heat-inactivated (HI) NHS, NHS + EDTA or medium. Representative examples of three replicate experiments are shown. (C-E) CDC of B cells obtained from 12 different CLL patients (patient B-M). CLL $B$ cells were opsonized with $16 \mu \mathrm{g} / \mathrm{mL}$ (C), $2 \mu \mathrm{g} / \mathrm{mL}$ (D) or $0.25 \mu \mathrm{g} / \mathrm{mL}$ (E) HxCD20-7D8 or Hx-CD37. The dashed line represents $95 \%$ cell lysis. CDC induction is expressed as the percentage lysis determined by the fraction of TO-PRO3 positive cells and data shown are mean and Standard Deviation of duplicate measurements. 
A

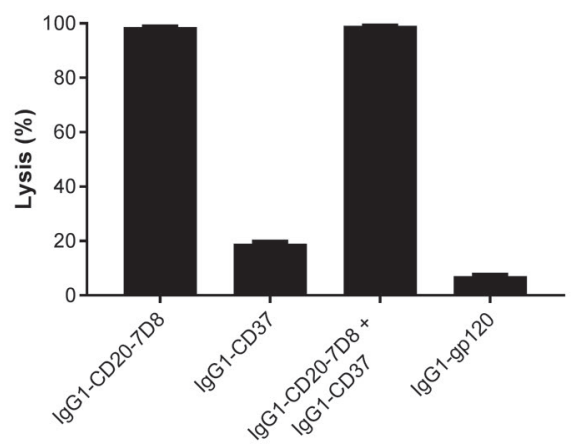

C

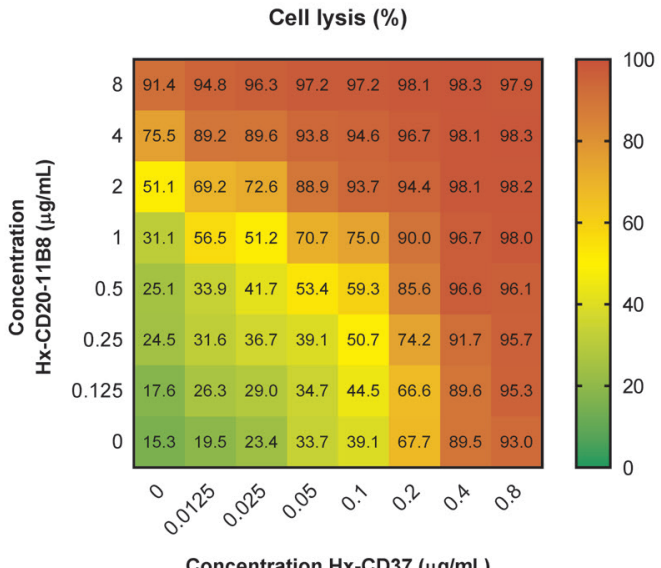

B

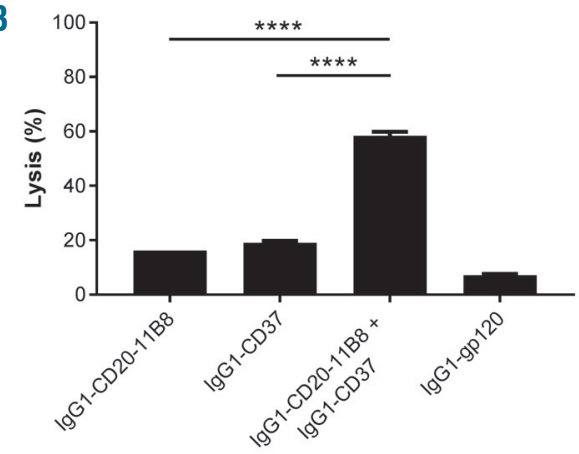

D

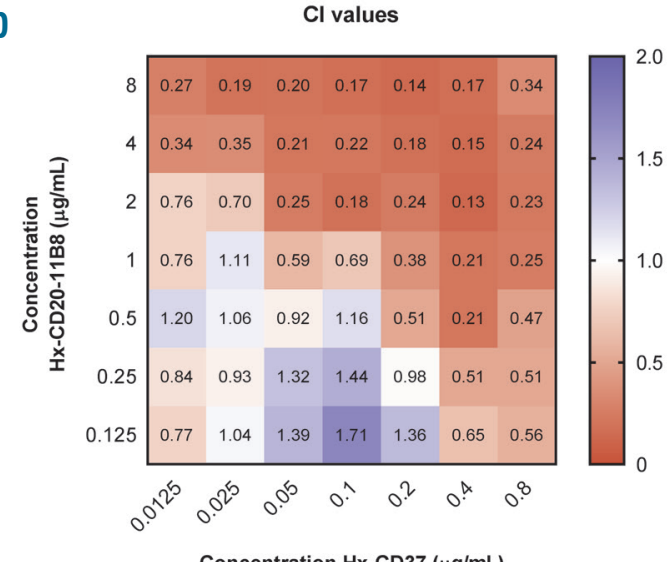

Concentration Hx-CD37 ( $\mu \mathrm{g} / \mathrm{mL})$

E
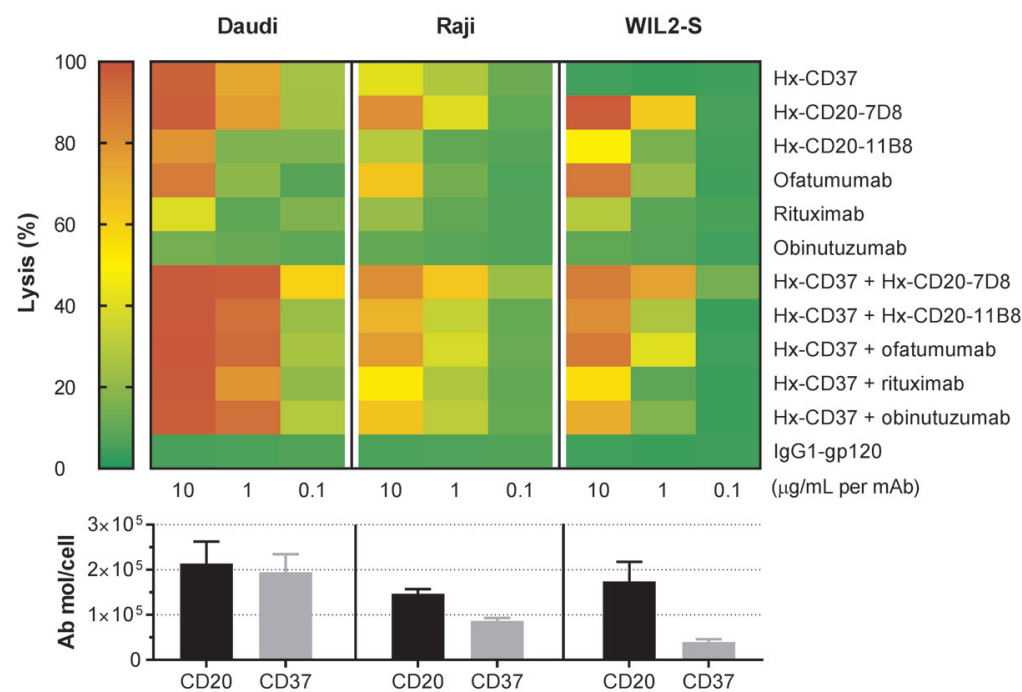

Figure 2. CD20 and CD37 mAbs synergistically induce complement-dependent cytotoxicity (CDC) of malignant B cells. (A and B) CDC on Daudi cells opsonized with $30 \mathrm{ug} / \mathrm{mL}$ wild-type (WT) type I CD20 mAb 7D8 (IgG1-CD20-7D8) (A) or type II CD20 mAb 11B8 (IgG1-CD20-11B8) (B), CD37 mAb 37.3 (IgG1-CD37), or a combination thereof $(15+15 \mathrm{ug} / \mathrm{mL})$ in the presence of $20 \% \mathrm{NHS}$. CDC induction is expressed as the percentage lysis determined by the fraction of propidium iodide (PI)-positive cells. Data shown are mean and Standard Deviation of triplicate measurements. (C) $8 \times 8$ CDC dose response matrix plot for the combination of hexamerizationenhanced CD37 mAb Hx-CD37 (0-0.8 $\mu \mathrm{g} / \mathrm{mL})$ with hexamerization-enhanced CD20 mAb Hx-CD20-11B8 (0-8 $\mu \mathrm{g} / \mathrm{mL})$, tested on Daudi cells and categorized as a color gradient from green (0\% lysis) to yellow (50\% lysis) to red (100\% lysis). HIV gp120-specific mAb b12 (IgG1-gp120) was used as a negative control human mAb. (D) Loewe additivity-based combination index (Cl) values calculated by CompuSyn for the $\mathrm{CDC}$ dose response matrix as described in (C) and categorized as synergistic $(<1$, red), additive (1, white) and antagonistic ( $>1$, blue). Representative examples of two replicate experiments are shown. (E) CDC and CD37 expression analysis on Daudi, Raji and WIL2-S cells. For the CDC assay, cells were opsonized with Hx-CD37 (10 $\mu \mathrm{g} / \mathrm{mL})$, different CD20 mAb variants $(10 \mu \mathrm{g} / \mathrm{mL})$ or combinations thereof $(10+10 \mathrm{\mu g} / \mathrm{mL})$. Data show the mean of nine replicates collected from three independent experiments. Expression levels were determined using QIFIKIT analysis. The number of antibody molecules per cell was calculated from the antibody-binding capacity (mean fluorescence intensity, MFI) normalized to a calibration curve, according to the manufacturer's guidelines. Expression data show the mean of four replicates collected from two independent experiments. ${ }^{*} * \star P<0.0001$. 
Colocalization of cell-bound CD20 and CD37 mAbs was further examined by directly assessing molecular proximity using fluorescence resonance energy transfer (FRET) analysis. We examined FRET on Daudi cells between WT and $\mathrm{Hx}$ variants of CD20 and CD37 mAbs alone and in combination. Consistent with its CDC activity (Figure 2A), WT IgG1-CD20-7D8 induced high FRET, which suggests antibody hexamer formation (Figure 4B). WT IgG1-CD20$11 \mathrm{~B} 8$ did not demonstrate proximity-induced FRET (Figure 4C), and WT IgG1-CD37 induced approximately 15\% FRET (Figure $4 \mathrm{~B}$ and $\mathrm{C}$ ). Introducing a Hx mutation resulted in increased FRET levels for each of the single agents, indicating that enhancing Fc-Fc interactions increases $\mathrm{mAb}$ colocalization at the cell surface $(P<0.0001)$ (Figure 4D and $\mathrm{E})$. Introduction of the $\mathrm{Hx}$ mutation did not affect target binding (data not shown), thereby excluding the possibility that increased FRET would be due to more mAb being available on the cell surface. Combinations of WT IgG1CD20-7D8 and WT IgG1-CD37 induced approximately $30 \%$ FRET, which was increased compared to the WT IgG1-CD37 single mAb $(P<0.0001$, Figure 4B). Combinations of WT IgG1-CD20-11B8 and WT IgG1CD37 substantially increased FRET compared to each single $\mathrm{mAb}(P<0.0001)$ (Figure $4 \mathrm{C})$, consistent with the enhanced CDC induction (Figure 2B). Combinations of $\mathrm{Hx}-\mathrm{CD} 20-7 \mathrm{D} 8$ or $\mathrm{Hx}-\mathrm{CD} 20-11 \mathrm{~B} 8$ with $\mathrm{Hx}-\mathrm{CD} 37$ further enhanced FRET compared to the FRET levels induced by the WT mAb combinations $(P<0.0001)$ (Figure $4 \mathrm{D}$ and $\mathrm{E})$. These results confirm that CD20 and CD37 IgG1 mAbs bind in close proximity on the cell membrane, which can be enhanced by introducing the E430G mutation.
Hexamerization-enhanced CD20 and CD37 mAbs cooperate in complement-dependent cytotoxicity through Fc-mediated clustering in hetero-hexamers

Both enhancing Fc-Fc interactions in the CD20 or CD37 $\mathrm{mAbs}$ and combining the two B-cell target mAbs resulted in enhanced $\mathrm{mAb}$ colocalization. Together with the dependency of CDC on the formation of hexameric IgG complexes on the cell surface, ${ }^{15}$ this suggests that the CD20 and CD37 mAbs might not only form hexamers composed of mAbs bound to identical surface targets, but may cooperate by also forming mixed hexameric complexes of $\mathrm{mAbs}$ bound to either target, referred to here as heterohexamers. The contribution of Fc-Fc interactions between $\mathrm{Hx}-\mathrm{CD} 20-11 \mathrm{~B} 8$ and Hx-CD37 to the CDC activity of the $\mathrm{mAb}$ combination was examined by the introduction of the complementary Fc-Fc interface mutations K439E and S440K. K439E and S440K suppress Fc-Fc interactions between antibody molecules containing the same mutation, whereas Fc-Fc interactions are restored in $\mathrm{K} 439 \mathrm{~K}$ and S440K antibody mixtures. ${ }^{15}$ The capacity of Hx-CD20$11 \mathrm{~B} 8$ and $\mathrm{Hx}-\mathrm{CD} 37$ variants with K439E and S440K mutations to induce CDC was tested using Daudi and WIL2-S cells. The CDC activity of Hx-CD20-11B8 was completely inhibited by introducing either the K439E or S440K Fc-Fc inhibiting mutation using Daudi and WIL2-S cells (Figure $5 \mathrm{~A}$ and $\mathrm{B})$. CDC activity was restored when Fc-Fc inhibition was neutralized by mixing the two CD20 mAbs. Similar results were observed for $\mathrm{Hx}-\mathrm{CD} 37$ on Daudi cells, while on WIL2-S cells, Hx-CD37 did not induce CDC, most likely due to low CD37 expression (Figure 5C and D). Combining $\mathrm{Hx}-\mathrm{CD} 20-11 \mathrm{~B} 8$ and $\mathrm{Hx}-\mathrm{CD} 37 \mathrm{mAbs}$ harbor-
A

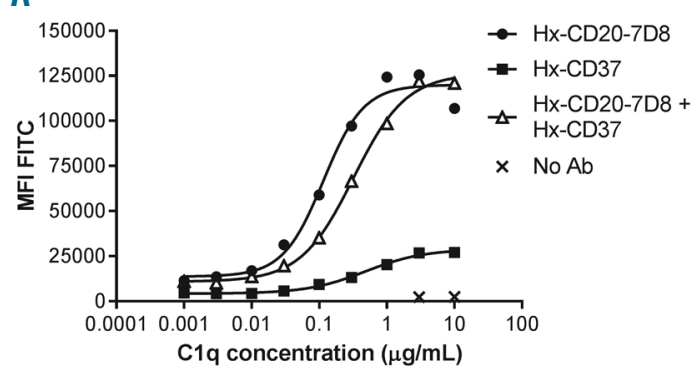

C

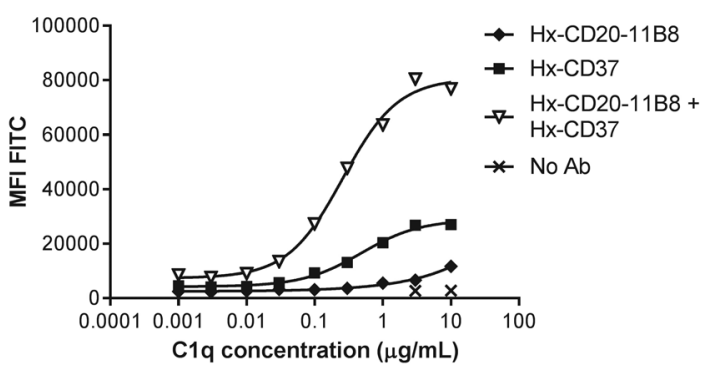

B

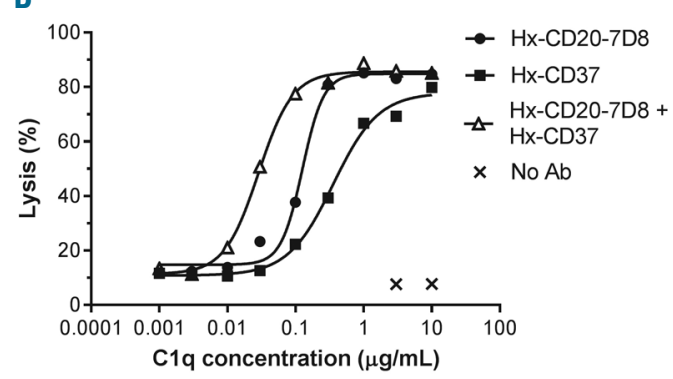

D

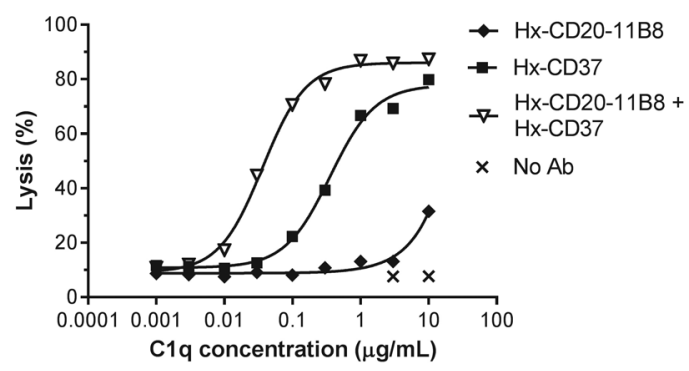

Figure 3. Enhanced binding and use of C1q by combinations of hexamerization-enhanced CD20 and CD37 mAbs. The capacity to bind C1q (A, C) and the efficiency to bind $\mathrm{C} 1 \mathrm{q}$ and promote Complement-dependent cytotoxicity (CDC) (B and D) was assessed using Daudi cells opsonized with $10 \mu \mathrm{g} / \mathrm{mL}$ of hexamerization-enhanced variants of type I CD20 mAb-derived Hx-CD20-7D8 (A-B) or type II CD20 mAb-derived Hx-CD20-11B8 (C and D), CD37 mAb 37.3-derived Hx-CD37, or a combination thereof $(5+5 \mu \mathrm{g} / \mathrm{mL})$. Binding was detected using a FITC-labeled rabbit anti-human C1q secondary antibody and is expressed as mean fluorescence intensity. CDC induction was assessed in C1q-depleted serum by calculating the percentage of propidium idodide (PI)-positive cells as determined by flow cytometry. Representative examples of three replicate experiments are shown. 
ing the same Fc-Fc inhibiting mutation (K439E or S440K) strongly reduced CDC activity on Daudi and WIL2-S cells (Figure 5E and F). However, CDC of both cell lines was restored by mixing $\mathrm{Hx}-\mathrm{CD} 20-11 \mathrm{~B} 8$ and $\mathrm{Hx}-\mathrm{CD} 37$, each carrying one of the complementary mutations K439E or S440K. These data suggest that Hx-CD20-11B8 and HxCD37 can indeed form hetero-hexameric complexes, thereby cooperating to activate complement.

A
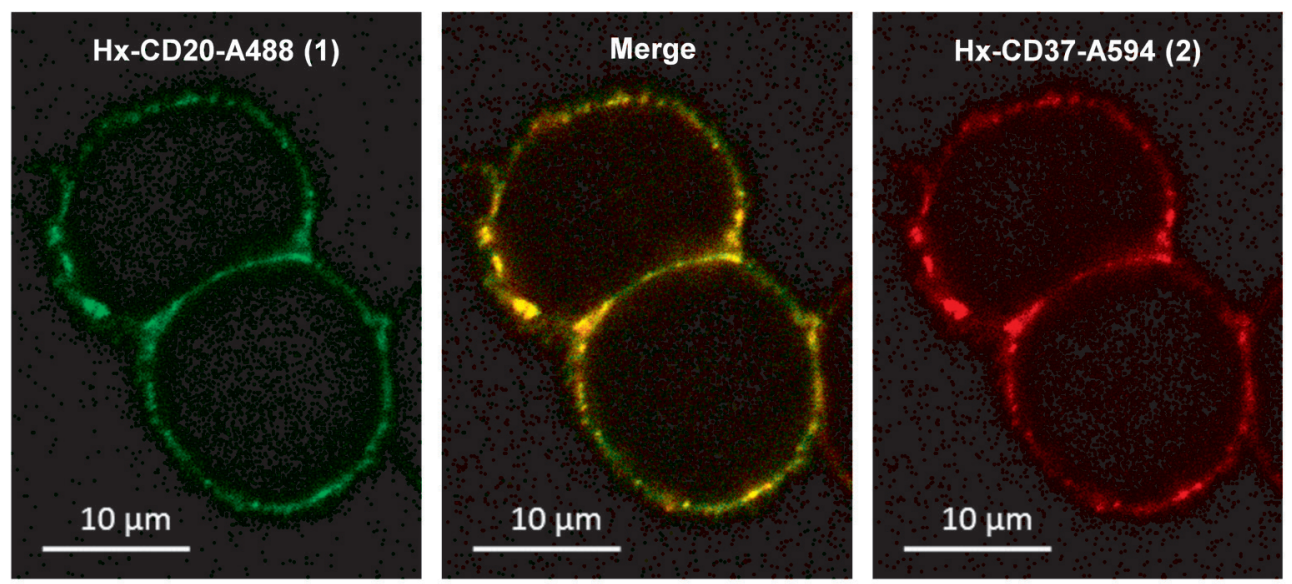

B

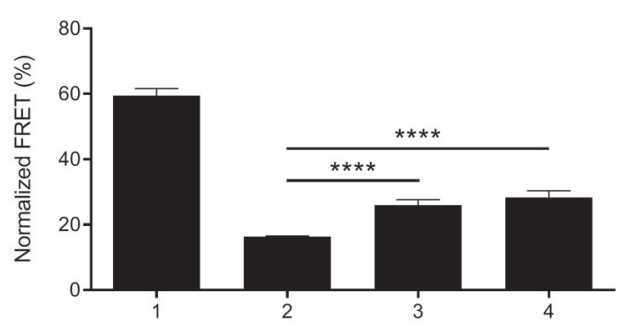

1. IgG1-CD20-7D8-A555 + IgG1-CD20-7D8-A647

2. $\lg$ G1-CD37-A555 + IgG1-CD37-A647

3. IgG1-CD20-7D8-A555 + IgG1-CD37-A647

4. IgG1-CD37-A555 + IgG1-CD20-7D8-A647

D

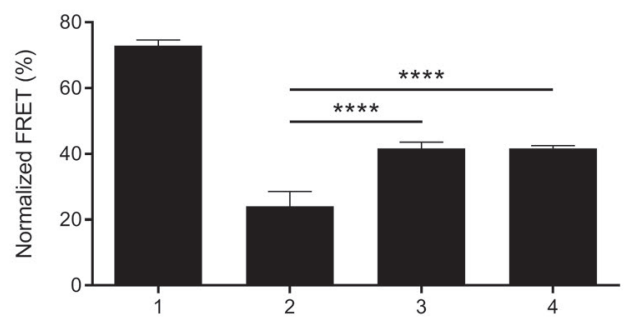

1. Hx-CD20-7D8-A555 + Hx-CD20-7D8-A647

2. $\mathrm{Hx}-\mathrm{CD} 37-\mathrm{A} 555+\mathrm{Hx}-\mathrm{CD} 37-\mathrm{A} 647$

3. Hx-CD20-7D8-A555 + Hx-CD37-A647

4. $\mathrm{Hx}-\mathrm{CD} 37-\mathrm{A} 555+\mathrm{Hx}-\mathrm{CD} 20-7 \mathrm{D} 8-\mathrm{A} 647$
C

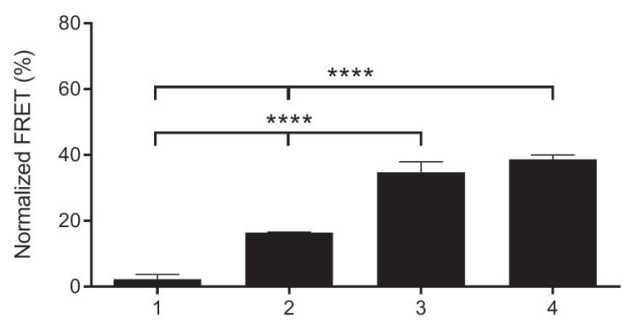

1. IgG1-CD20-11B8-A555 + IgG1-CD20-11B8-A647

2. IgG1-CD37-A555 + IgG1-CD37-A647

3. IgG1-CD20-11B8-A555 + IgG1-CD37-A647

4. IgG1-CD37-A555 + IgG1-CD20-11B8-A647

$\mathrm{E}$

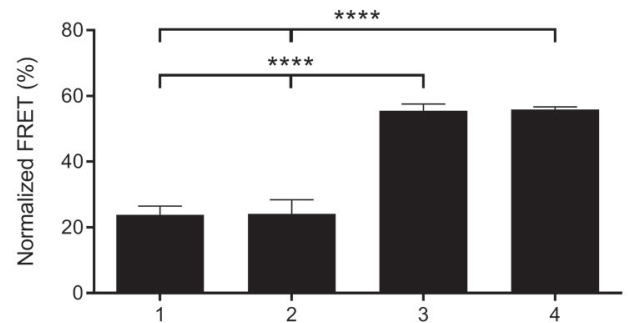

1. Hx-CD20-11B8-A555 + Hx-CD20-11B8-A647

2. $\mathrm{Hx}-\mathrm{CD} 37-\mathrm{A} 555+\mathrm{Hx}-\mathrm{CD} 37-\mathrm{A} 647$

3. Hx-CD20-11B8-A555 + Hx-CD37-A647

4. Hx-CD37-A555 + Hx-CD20-11B8-A647

Figure 4. CD20 and CD37 mAbs colocalize on B cells. (A) Confocal fluorescence microscopy analysis to detect colocalization of cell-bound CD20 and CD37 mAbs. Raji cells were opsonized with hexamerization-enhanced A488-conjugated CD20 mAb 7D8-derived Hx-CD20-7D8 (image 1, green) and hexamerization-enhanced A594-conjugated CD37 mAb 37.3-derived Hx-CD37 (image 2, red), and incubated for 15 minutes ( $\mathrm{min}$ ) at room temperature. Images were captured in PBS imaging medium at ambient temperature using a Zeiss Axi-oObserver LSM 700 microscope with Plan-Apochromat 63X/1.40 Oil DIC M27 objective lenses and acquired/processed using Zen software. Two excitation lasers were used at 488 and $555 \mathrm{~nm}$. In the merged image, overlap of red and green produces orange or yellow. A representative example of two replicate experiments is shown. (B and C) FRET analysis to detect the molecular proximity of (B) WT type I CD20 mAb 7D8 (IgG1-CD20-7D8) or (C) WT type II CD20 mAb 11B8 (IgG1-CD20-11B8), WT CD37 mAb 37.3 (IgG1-CD37) or a combination thereof on the cell membrane of Daudi cells. (D and E) FRET analysis to detect the molecular proximity of hexamerization enhanced variants of (D) type I CD20 mAb 7D8-derived Hx-CD20-7D8 or (E) type II CD20 mAb 11B8-derived Hx-CD20-11B8, CD37 mAb 37.3-derived Hx-CD37 or a combination thereof on the cell membrane of Daudi cells. Daudi cells were opsonized with $10 \mu \mathrm{g} / \mathrm{mL} \mathrm{A} 555-\mathrm{conjugated-}$ and $10 \mu \mathrm{g} / \mathrm{mL}$ A647-conjugated antibody variants for $15 \mathrm{~min}$ at $37^{\circ} \mathrm{C}$. FRET was calculated from mean fluorescence intensity values as determined by flow cytometry. Data shown are mean and Standard Deviation of six replicates collected from three independent experiments. $* * * *<0.0001$. 


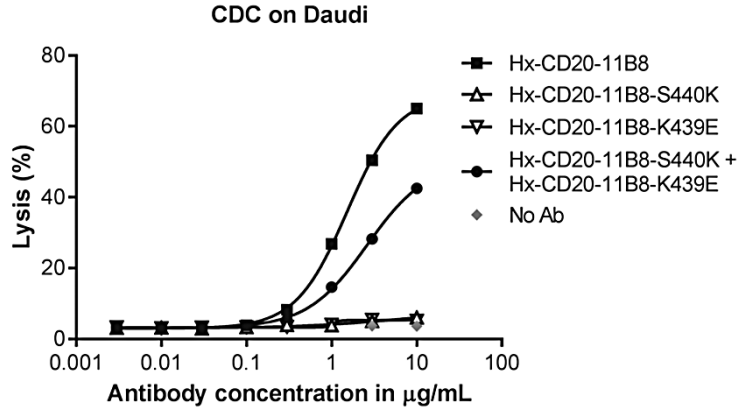

C

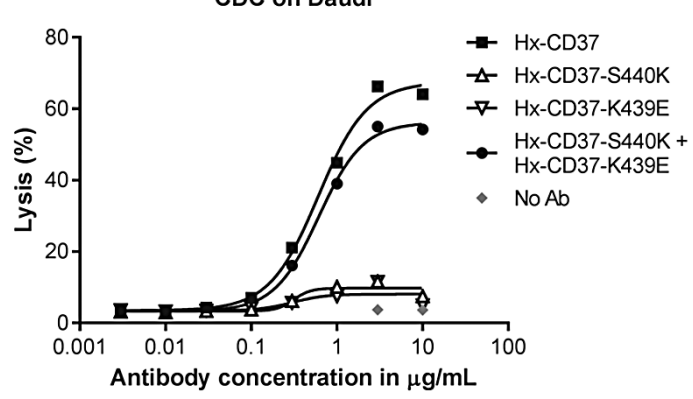

E

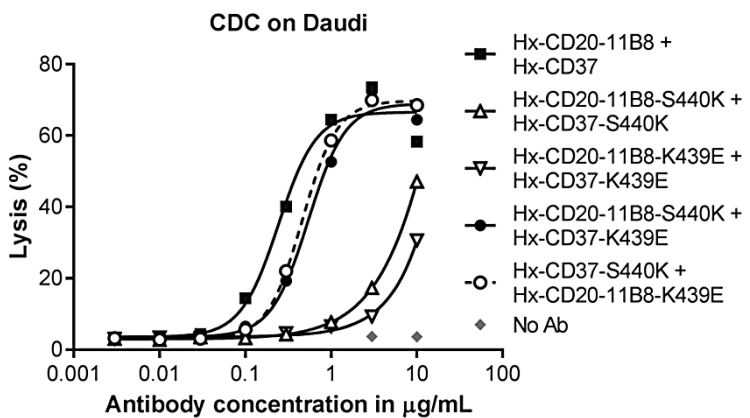

B

CDC on WIL2-S

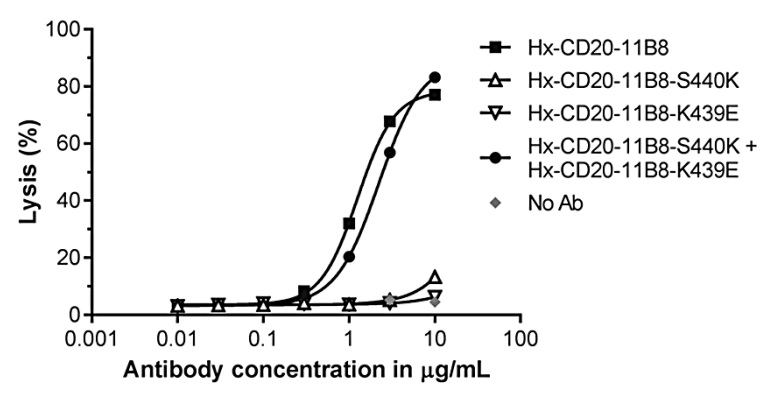

D

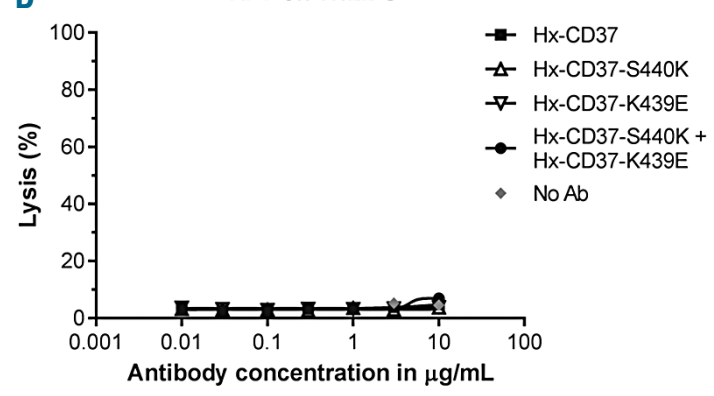

$\mathrm{F}$

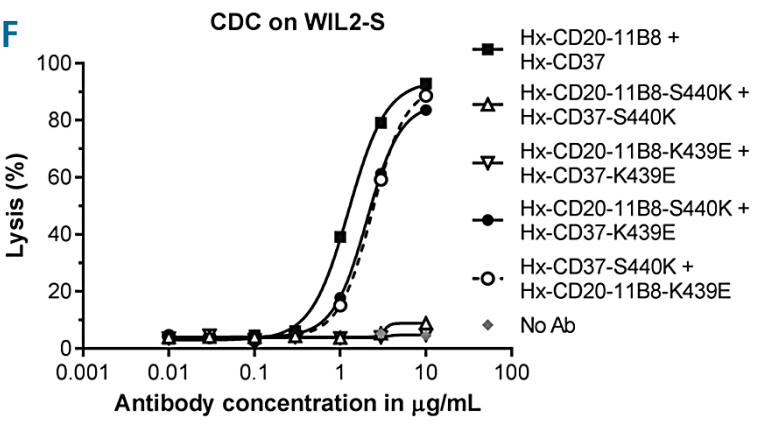

G

FRET on Daudi

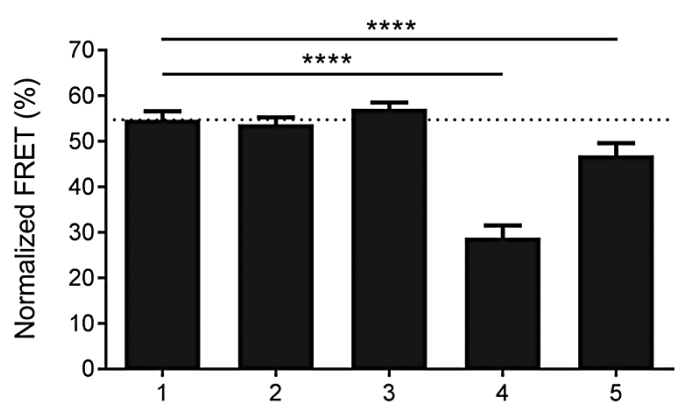

1. $\mathrm{Hx}-\mathrm{CD} 20-11 \mathrm{~B} 8-\mathrm{A} 555+\mathrm{Hx}-\mathrm{CD} 37-\mathrm{A} 647$

2. Hx-CD20-11B8-K439E-A555 + Hx-CD37-S440K-A647

3. Hx-CD20-11B8-S440K-A555 + Hx-CD37-K439E-A647

4. Hx-CD20-11B8-K439E-A555 + Hx-CD37-K439E-A647

5. Hx-CD20-11B8-S440K-A555 + Hx-CD37-S440K-A647

Figure 5. Hexamerization-enhanced CD20 and CD37 mAb cooperate in complement-dependent cytotoxicity (CDC) through Fc-mediated clustering in hetero-hexamers. The effect of introducing Fc-Fc inhibiting mutations S440K and K439E on the CDC induction of hexamerization-enhanced type II CD20 mAb 11B8-derived HxCD20-11B8 on Daudi cells (A) and WIL2-S cells (B), hexamerization-enhanced CD37 mAb 37.3-derived Hx-CD37 on Daudi (C) and WIL2-S cells (D) and the mAb combinations thereof on Daudi (E) and WIL2-S cells (F). Cells were opsonized with concentration series of Hx-CD20-11B8 and Hx-CD37 variants in the presence of 20\% NHS. CDC induction is expressed as the percentage lysis determined by the fraction of propidium iodide (PI)-positive cells. Representative examples of two (WIL-2S) and three replicates (Daudi) are shown. (G) The effect of introducing Fc-Fc inhibiting mutations S440K and K439E on the molecular proximity of Hx-CD20-11B8 and $\mathrm{Hx}$-CD37 variants on the cell membrane of Daudi cells. Daudi cells were incubated with $10 \mu \mathrm{g} / \mathrm{mL}$ A555-conjugated Hx-CD20-11B8 variants and $10 \mu \mathrm{g} / \mathrm{mL}$ A647conjugated $\mathrm{Hx}$-CD37 variants for 15 minutes at $37^{\circ} \mathrm{C}$. FRET was calculated from the mean fluorescence intensity values as determined by flow cytometry. Data shown are mean and Standard Deviation of six replicates collected from three independent experiments. $* * * * P<0.0001$. 
Next, the effect of the Fc-Fc interaction-inhibiting mutations on colocalization of Hx-CD20-11B8 and Hx-CD37 mAbs on the cell membrane of Daudi cells was evaluated using FRET analysis. mAb combinations with $\mathrm{Hx}-\mathrm{CD} 20$ $11 \mathrm{~B} 8$ and $\mathrm{Hx}-\mathrm{CD} 37$ variants, both harboring the same FcFc inhibiting mutation (K439E or S440K) showed reduced FRET on Daudi cells (Figure 5G and Online Supplementary Figure S6). FRET levels were restored when Fc-Fc inhibition was neutralized by combining Hx-CD20-11B8 and $\mathrm{Hx}-\mathrm{CD} 37 \mathrm{mAbs}$, each having one of the complementary mutations K439E or S440K. Thus, donor- and acceptorlabeled $\mathrm{Hx}-\mathrm{CD} 20-11 \mathrm{~B} 8$ and $\mathrm{Hx}-\mathrm{CD} 37 \mathrm{mAb}$ variants come together in close proximity on the cell membrane of Daudi cells, which appears to be, at least in part, mediated by the Fc domain.
Combinations of hexamerization-enhanced CD20 and CD37 mAbs induce superior ex vivo complement-dependent cytotoxicity of tumor cells obtained from patients with B-cell malignancies

We next examined the capacity of combinations of $\mathrm{Hx}$ CD20 and $\mathrm{Hx}-\mathrm{CD} 37 \mathrm{mAbs}$ to induce CDC ex vivo in tumor cells obtained from patients with B-cell malignancies. First, the CDC activity of Hx-CD20-7D8, Hx-CD37 or combinations was evaluated using tumor cells obtained from 15 patients diagnosed with CLL. Both Hx-CD20$7 \mathrm{D} 8$ and $\mathrm{Hx}-\mathrm{CD} 37$ induced substantial CDC of CLL tumor cells from all 15 tested donors (Figure 6A), in accordance with that seen in Figure 1. $\mathrm{Hx}-\mathrm{CD} 37$ was more effective in CDC than Hx-CD20-7D8, which may be explained by higher expression CD37 on CLL cells

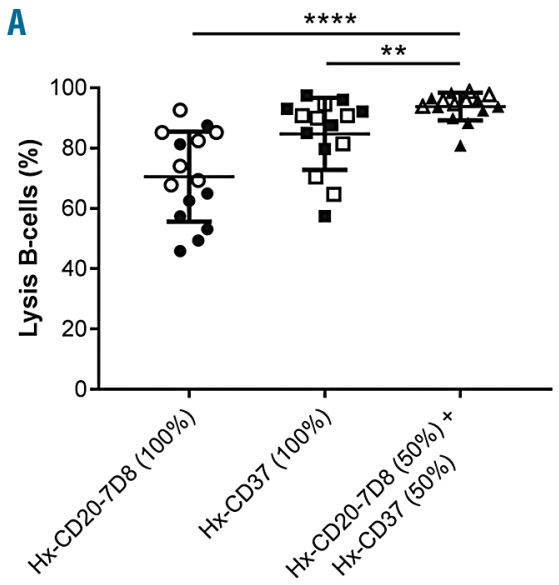

B

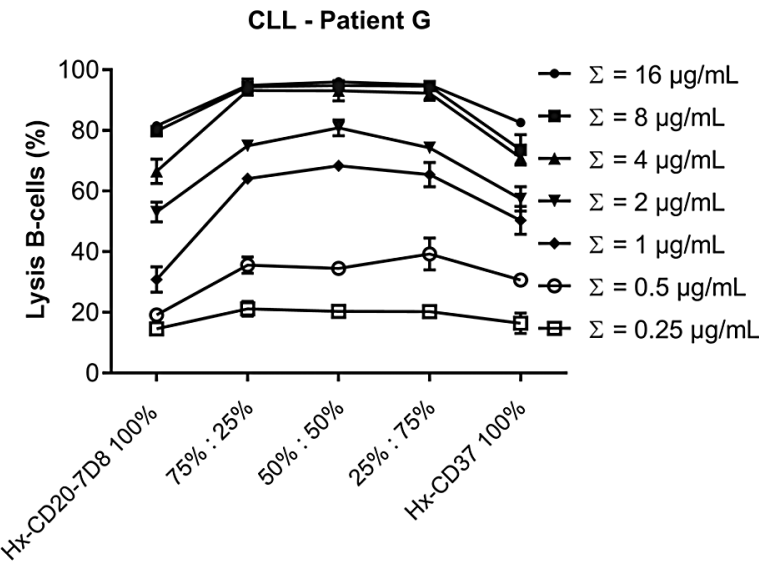

D
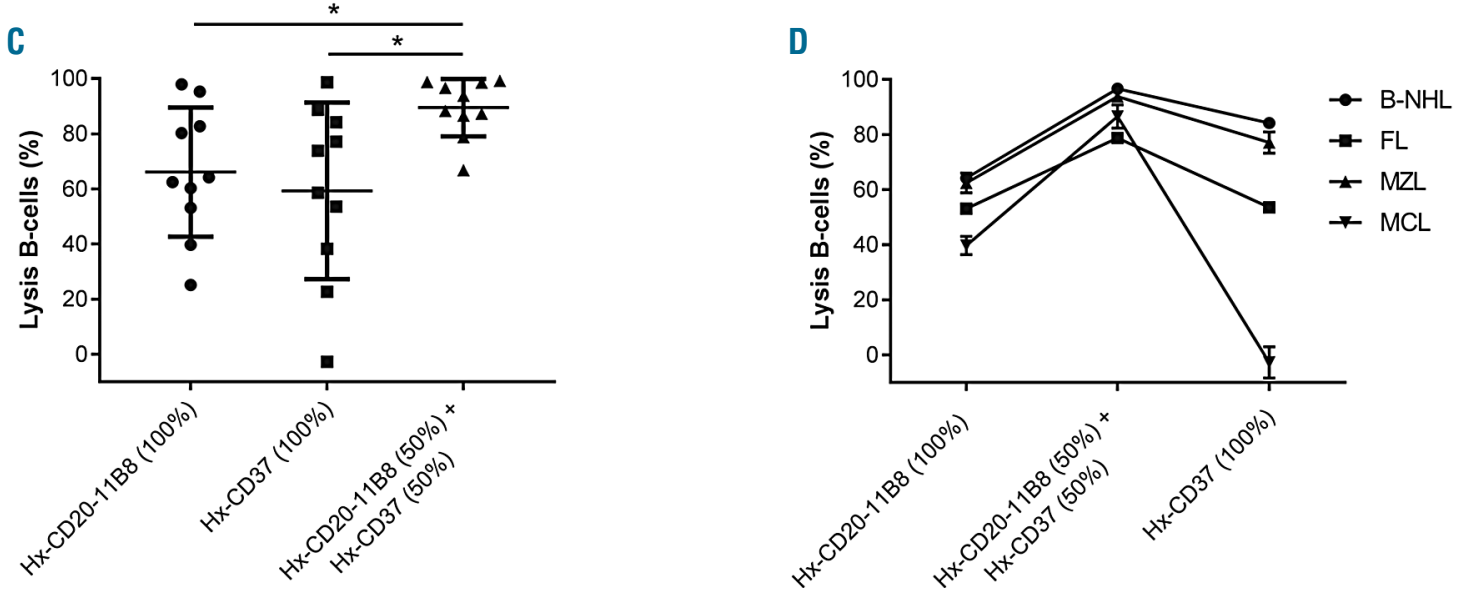

Figure 6. Combinations of hexamerization-enhanced CD20 and CD37 monoclonal antibodies (mAbs) induce superior ex vivo complement-dependent cytotoxicity (CDC) of tumor cells obtained from patients with B-cell malignancies. (A) B cells obtained from 15 patients diagnosed with chronic lymphocytic leukemia (CLL) were opsonized with fixed concentrations of hexamerization-enhanced type I CD20 mAb 7D8-derived Hx-CD20-7D8 or hexamerization-enhanced CD37 mAb 37.3-derived Hx-CD37 (open symbols: $2.5 \mu \mathrm{g} / \mathrm{mL}$, closed symbols: $2 \mu \mathrm{g} / \mathrm{mL}$; each presented as $100 \%$ ), or 1:1 mixtures thereof (open symbols: $0.625 \mu \mathrm{g} / \mathrm{mL}$ of each mAb, closed symbols: $0.5 \mu \mathrm{g} / \mathrm{mL}$ of each mAb; each represented as 50\%) in the presence of $50 \%$ NHS. CDC induction is presented as the percentage lysis determined by the fraction of TO-PRO-3 positive cells. (B) B cells of a representative CLL patient sample (patient G) were opsonized with different total mAb concentrations of Hx-CD20$7 \mathrm{D} 8$ or $\mathrm{Hx}$-CD37 (single agents indicated as 100\%) and combinations thereof at different antibody ratios (indicated as $75 \%: 25 \%, 50 \%: 50 \%$ and $25 \%: 75 \%$ ) in the presence of $50 \%$ NHS. CDC induction is presented as the percentage lysis determined by the fraction of TO-PRO-3 positive cells. Data shown are mean and Standard Deviation of duplicate measurements. (C) B cells obtained from ten patients diagnosed with different B-cell malignancies [B-cell non-Hodgkin lymphoma (B-NHL) not otherwise specified (NOS), follicular lymphoma (FL), marginal zone lymphoma (MZL) and mantle cell lymphoma (MCL)] were opsonized with $10 \mu \mathrm{g} / \mathrm{mL}$ of hexamerization-enhanced type II CD20 mAb 11B8-derived Hx-CD20-11B8 or Hx-CD37, and the combination thereof $(5+5 \mu \mathrm{g} / \mathrm{mL})$ in the presence of $20 \% \mathrm{NHS}$. CDC induction is presented as the percentage lysis determined by the fraction of 7-AAD positive B-lymphoma cells. (D) CDC assay with B-cell patient samples representative for BNHL (NOS), FL, MZL and MCL as described in (C). Data shown are mean and Standard Deviation of duplicate measurements. ${ }^{\star} P<0.05 ; * \star P<0.01 ; * * * * P<0.0001$. 
$(P<0.05)$ (Online Supplementary Figure $S 3 A$ and $B)$. Importantly, significantly increased CDC levels were observed in 9 of 15 tested CLL donors upon treatment with the combination of $\mathrm{Hx}-\mathrm{CD} 20-7 \mathrm{D} 8$ and $\mathrm{Hx}-\mathrm{CD} 37$. Even at modest total concentrations of $\mathrm{Hx}-\mathrm{CD} 20-7 \mathrm{D} 8$ and $\mathrm{Hx}-\mathrm{CD} 37$ ( $\leq 1.25 \mu \mathrm{g} / \mathrm{mL}$ for each $\mathrm{mAb}),>90 \% \mathrm{CDC}$ of B cells was induced in 12 of the 15 tested CLL donors (Figure $6 \mathrm{~A})$. Enhanced $\mathrm{CDC}$ by the $\mathrm{mAb}$ combination was observed over a range of $\mathrm{mAb}$ concentrations and at different $\mathrm{mAb}$ ratios, and was more apparent at lower $\mathrm{mAb}$ concentrations, as illustrated for one representative donor (Figure 6B). Next, we evaluated the cytotoxic capacity of $\mathrm{Hx}-\mathrm{CD} 20-11 \mathrm{~B} 8, \mathrm{Hx}-\mathrm{CD} 37$, and the combination thereof using tumor cells of ten patients diagnosed with different B-cell lymphomas, including B-cell non-Hodgkin lymphoma (B-NHL) not otherwise specified (NOS), follicular lymphoma (FL), marginal zone lymphomas (MZL) and mantle cell lymphoma (MCL). While for the single agents a large variation in CDC efficacy was observed between the donors, the combination of Hx-CD20-11B8 and Hx-CD37 consistently showed enhanced CDC activity compared to the individual mAbs (Figure 6C). Representative figures from each tested lymphoma subtype show that combinations of $\mathrm{Hx}-\mathrm{CD} 20-11 \mathrm{~B} 8$ and $\mathrm{Hx}-\mathrm{CD} 37$ at the tested 1:1 ratio may enhance CDC, even when CDC induced by the individual mAbs was low or absent (Figure 6D). Furthermore, analysis of CD20 and CD37 target expression levels on primary B cells from 24 CLL patients and ten patients with different NHL subtypes illustrated a large diversity in target expression levels and ratios (Online Supplementary Figure S3A-C). These results suggest that combinations of $\mathrm{Hx}-\mathrm{CD} 20$ and $\mathrm{Hx}$ CD37 mAbs may generally increase the therapeutic potential of CDC-inducing $\mathrm{mAbs}$ in B-cell malignancies across different target expression levels and ratios.

\section{Discussion}

Improving therapeutic efficacy against (heterogeneous) tumors has been the focus of intense preclinical and clinical development. We previously showed that the therapeutic

\section{A General principle of hexamer formation}

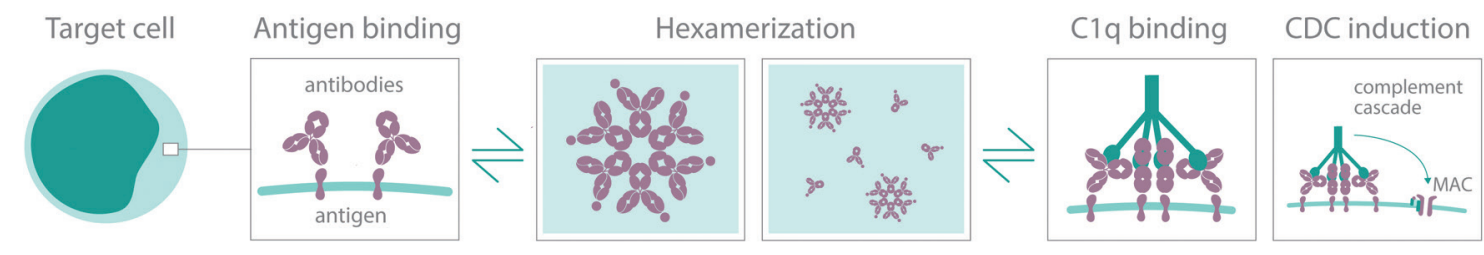

B Schematic representation of hexamer formation by CD20 and CD37 antibodies
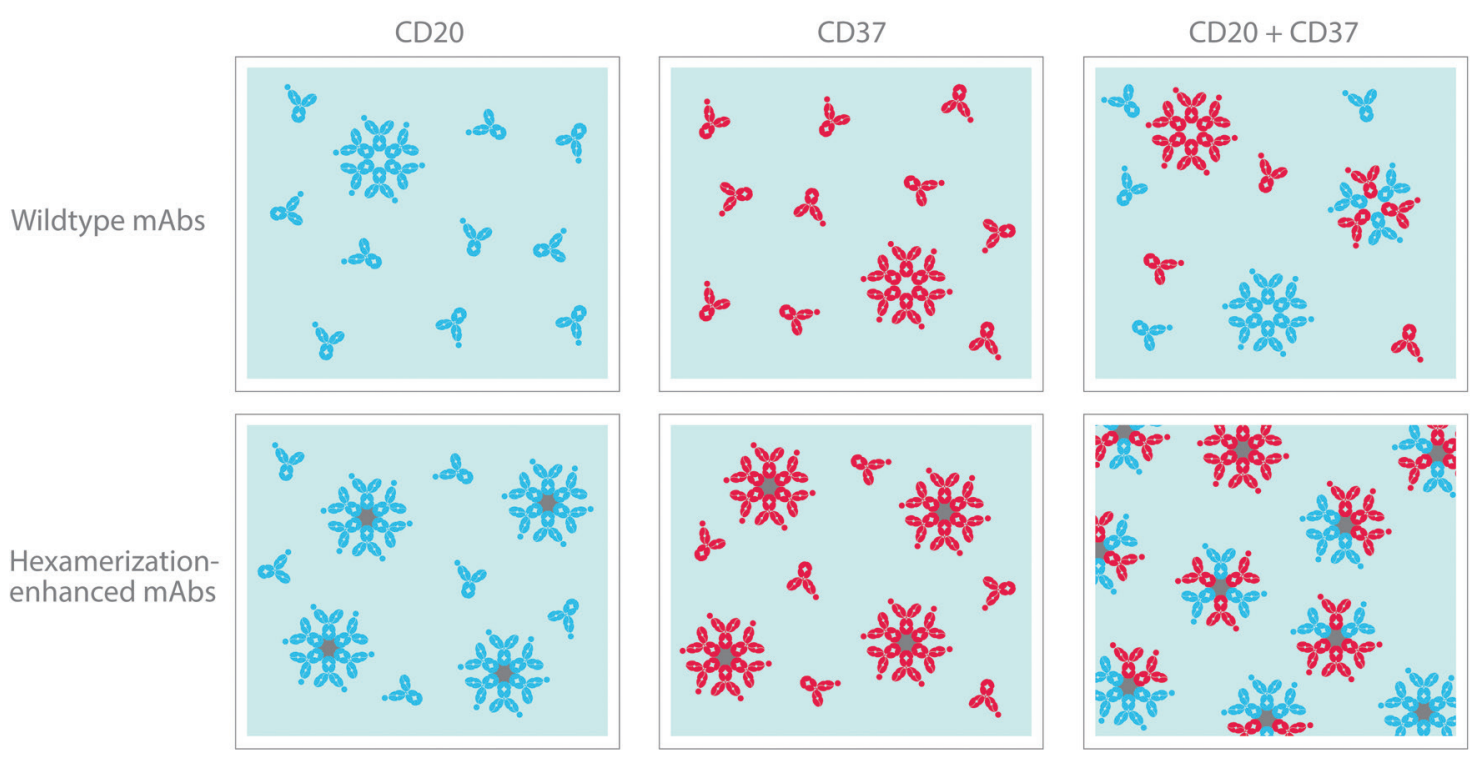

Figure 7. Model for Fc-mediated clustering of CD20 and CD37 monoclonal antibodies (MAbs) in hetero-hexamers upon binding to the cell surface. (A) mAbs naturally cluster into hexameric complexes upon antibody binding to a cognate antigen on a target cell, thereby providing a docking site for $\mathrm{C} 1 \mathrm{q}$ binding and complementdependent cytotoxicity (CDC) induction. (B) Upon binding of mAbs targeting two different coexpressed antigens on the plasma membrane that (are able to) colocalize, hetero-hexameric antibody complexes are formed consisting of both mAbs, providing a docking site for C1q binding and CDC induction. Introducing hexamerizationenhancing mutations can increase Fc-mediated clustering of mAbs, both into homo- and hetero-hexameric antibody complexes on the cell surface, thereby increasing the number of $\mathrm{C} 1 \mathrm{q}$ docking sites and further potentiating $\mathrm{CDC}$. 
potential of IgG1 mAbs can be enhanced by introducing mutations that improve hexamerization by Fc-mediated clustering and thereby increase CDC activity. ${ }^{15,16}$ In the present study, we introduced a $\mathrm{Hx}$ mutation, E430G, into CD20 and CD37 mAbs and observed an impressive increase in CDC activity in primary CLL samples. Moreover, combinations of CD20 and CD37 mAbs showed enhanced and synergistic CDC activity, including combinations of $\mathrm{Hx}-\mathrm{CD} 37 \mathrm{mAbs}$ with the approved $\mathrm{mAbs}$ rituximab, ofatumumab and obinutuzumab. With several CD20 and CD37 mAbs approved or in clinical development, it is attractive to study the mechanism behind the cooperativity between mAbs targeting these two antigens. ${ }^{34,35}$ It was recently reported that expression levels of CD20 and CD37 mRNA and protein are correlated on lymphoma $\mathrm{B}$ cells. ${ }^{36}$ Here, using confocal microscopy and FRET analysis we show that CD20 and CD37 mAbs colocalize on surfaces of $\mathrm{B}$ cells and that enhancing Fc-Fc interactions increases $\mathrm{mAb}$ colocalization. The observed synergistic CDC activity of CD20 and CD37 mAbs was supported by increased $\mathrm{C} 1 \mathrm{q}$ binding and increased CDC efficacy, as illustrated by enhanced CDC at relatively low C1q concentrations. Synergy in complement activation was most evident for CD37 mAbs in combination with type II CD20 mAbs, than with type I CD20 mAbs which are already effective at clustering as WT mAbs.

De Winde et al. ${ }^{37}$ recently suggested that the organization of the B-cell plasma membrane is shaped by dynamic protein-protein interactions and that this organization might be altered by targeted $\mathrm{mAb}$ therapies. It has previously been described that membrane proteins can cluster into lipid rafts or tetraspanin-enriched microdomains (TEM), enabling efficient signal transduction. ${ }^{38,39}$ We hypothesized that the synergistic interactions in CDC between CD20 and CD37 mAbs could be driven by clustering of both target-bound $\mathrm{mAbs}$ into oligomeric complexes. By introducing Fc-Fc inhibiting mutations, we were able to demonstrate that CD20 and CD37 mAbs do not only permit the formation of homo-hexamers consisting of $\mathrm{mAbs}$ bound to either single target separately, but also allow the formation of hetero-hexamers composed of alternating CD20 and CD37 mAbs, each bound to their own cognate target, explaining the synergistic effects. Other hetero-hexamer variants may occur, although the presence of such alternative variants remains to be demonstrated (see Figure 7). We therefore propose a model for Fc-mediated clustering of synergistic $\mathrm{mAb}$ combinations on malignant B cells (Figure 7). Upon binding of mAbs targeting two different coexpressed antigens on the plasma membrane that are able to colocalize, hetero-hexameric complexes are formed, provid- ing a docking site for $\mathrm{C} 1 \mathrm{q}$ binding and CDC induction. Introducing hexamerization-enhancing mutations can increase Fc-mediated clustering of $\mathrm{mAb}$ into both homoand hetero-hexameric complexes, thereby increasing the number of hexamers and further potentiating CDC. Increasing the therapeutic potency of $\mathrm{mAb}$ combinations, driven by hetero-hexamerization, could be of clinical relevance, as illustrated by a combination of $\mathrm{Hx}-\mathrm{CD} 20$ and $\mathrm{Hx}$-CD37 mAbs that showed strong CDC of tumor B cells obtained from patients with different B-cell malignancies. Hicks et al..$^{40}$ recently reported that the antitumor activity of IMGN529, a CD37-targeting antibody-drug conjugate in clinical development, was potentiated in combination with rituximab in vivo in B-NHL xenograft models, which was associated with increased CD37 internalization rates. Other mechanisms of synergy between CD20 and CD37 have also been reported, such as upregulation of CD20 expression in Daudi cells after treatment with the radiolabeled anti-CD37 $\mathrm{mAb}$ 177Lu-lilotomab. ${ }^{41}$

The concept of antibody hetero-hexamer formation may hold relevance for a broader range of targets and effector mechanisms. An emerging therapeutic approach is the development of designer polyclonals, consisting of multiple $\mathrm{mAbs}$ in one product of which several are in clinical development, such as MM-151, targeting three epitopes on EGFR and Sym013, a mixture of six mAbs targeting all three HER family members (EGFR, HER2 and HER3). ${ }^{42,43}$ One could speculate that enhancing Fc-mediated antibody clustering involving different coexpressing targets on hematologic or solid tumors may induce synergistic efficacy, providing a rationale for application in designer polyclonals. Whether effector mechanisms other than CDC, such as ADCC or ADCP are also enhanced by combinations of CD20 and CD37 mAbs remains to be elucidated. One may speculate that the engagement of two mAbs binding coexpressed targets allows for higher total antibody binding on the cell surface, allowing more efficient engagement of Fc $\gamma$ Rs on effector cells.

In the present work, we have demonstrated that synergy in CDC induced by combinations of CD20 and CD37 $\mathrm{mAbs}$ is likely driven by Fc-mediated clustering into hetero-hexameric antibody complexes on the cell surface. Enhancing hetero-hexamerization between $\mathrm{mAb}$ combinations using Fc engineering represents a powerful tool to increase the therapeutic efficacy of $\mathrm{mAb}$ combinations directed against hematologic and other tumor targets.

\section{Acknowledgments}

The authors would like to thank Joost Bakker (SCICOMVISUALS) for designing Figure 7.

\section{References}

1. Deans JP, Li H, Polyak MJ. CD20-mediated apoptosis: signalling through lipid rafts. Immunology. 2002;107(2):176-182.

2. Gopal AK, Press OW. Clinical applications of anti-CD20 antibodies. Transl Res. 1999; 134(5):445-450.

3. Leget GA, Czuczman MS. Use of rituxim $A b$, the new FDA-approved antibody. Curr Opin Oncol. 1998;10(6):548-551.
4. Beurskens FJ, Lindorfer MA, Farooqui M, et al. Exhaustion of cytotoxic effector systems may limit $\mathrm{mAb}$-based immunotherapy in cancer patients. J Immunol. 2012; 188(7):3532-3541.

5. Taylor RP, Lindorfer MA. Analyses of CD20 Monoclonal Antibody-Mediated Tumor Cell Killing Mechanisms: Rational Design of Dosing Strategies. Mol Pharmacol. 2014;86(5):485-491.

6. Weiner GJ. Building better monoclonal antibody-based therapeutics. Nat Rev Cancer. 2015;15(6):361-370.
7. Wang X, Mathieu M, Brezski RJ. IgG Fc engineering to modulate antibody effector functions. Protein Cell. 2018;9(1):63-73.

8. Lazar GA, Dang W, Karki S, et al. Engineered antibody $\mathrm{Fc}$ variants with enhanced effector function. Proc Natl Acad Sci U S A. 2006;103(11):4005-4010.

9. Richards JO, Karki S, Lazar GA, Chen H, Dang W, Desjarlais JR. Optimization of antibody binding to Fc RIIa enhances macrophage phagocytosis of tumor cells. Mol Cancer Ther. 2008;7(8):2517-2527.

10. Shields RL, Namenuk AK, Hong K, et al 
High Resolution Mapping of the Binding Site on Human IgG1 for Fcgamma RI, Fcgamma RII, Fcgamma RIII, and FcRn and Design of IgG1 Variants with Improved Binding to the Fcgamma R. J Biol Chem. 2000;276(9):6591-6604.

11. Stavenhagen JB, Gorlatov S, Tuaillon N, et al. Fc Optimization of Therapeutic Antibodies Enhances Their Ability to Kill Tumor Cells In vitro and Controls Tumor Expansion In vivo via Low-Affinity Activating Fc Receptors. Cancer Res. 2007;67(18):8882-8890.

12. Idusogie EE, Wong PY, Presta LG, et al. Engineered antibodies with increased activity to recruit complement. J Immunol. 2001;166(4):2571-2575

13. Natsume $\mathrm{A}$, In $\mathrm{M}$, Takamura $\mathrm{H}$, et al. Engineered Antibodies of IgG1/IgG3 Mixed Isotype with Enhanced Cytotoxic Activities. Cancer Res. 2008;68(10):3863-3872.

14. Melis JPM, Strumane K, Ruuls SR, Beurskens FJ, Schuurman J, Parren PWHI. Complement in therapy and disease: Regulating the complement system with antibody-based therapeutics. Mol Immunol. 2015;67(2, Part A):117-130.

15. Diebolder CA, Beurskens FJ, de Jong RN, et al. Complement Is Activated by IgG Hexamers Assembled at the Cell Surface. Science. 2014;343(6176):1260-1263.

16. de Jong RN, Beurskens FJ, Verploegen S, et al. A Novel Platform for the Potentiation of Therapeutic Antibodies Based on AntigenDependent Formation of IgG Hexamers at the Cell Surface. PLoS Biol. 2016; 14(1):e1002344

17. Lindorfer MA, Cook EM, Tupitza JC, et al. Real-time analysis of the detailed sequence of cellular events in mAb-mediated complement-dependent cytotoxicity of B-cell lines and of chronic lymphocytic leukemia B-cells. Mol Immunol. 2016;70:13-23.

18. Teeling JL, French RR, Cragg MS, et al. Characterization of new human CD20 monoclonal antibodies with potent cytolytic activity against non-Hodgkin lymphomas. Blood. 2004;104(6):1793-1800.

19. Dechant M, Weisner W, Berger S, et al. Complement-Dependent Tumor Cell Lysis Triggered by Combinations of Epidermal Growth Factor Receptor Antibodies. Cancer Res. 2008;68(13):4998-5003.

20. Klausz K, Berger S, Lammerts van Bueren JJ, et al. Complement mediated tumor specific cell lysis by antibody combinations targeting epidermal growth factor receptor (EGFR) and its variant III (EGFRvIII).
Cancer Sci. 2011;102(10):1761-1768.

21. Link MP, Bindl J, Meeker TC, et al. A unique antigen on mature $\mathrm{B}$ cells defined by a monoclonal antibody. J Immunol. 1986;137(9):3013-3018.

22. Schwartz-Albiez R, Dörken B, Hofmann W, Moldenhauer G. The B cell-associated CD37 antigen (gp40-52). Structure and subcellular expression of an extensively glycosylated glycoprotein. J Immunol. 1988; 140(3):905-914

23. Deckert J, Park PU, Chicklas S, et al. A novel anti-CD37 antibody-drug conjugate with multiple anti-tumor mechanisms for the treatment of B-cell malignancies. Blood. 2013;122(20):3500-3510

24. Heider K-H, Kiefer K, Zenz T, et al. A novel Fc-engineered monoclonal antibody to CD37 with enhanced ADCC and high proapoptotic activity for treatment of B-cell malignancies. Blood. 2011;118(15):41594168 .

25. Pereira DS, Guevara CI, Jin L, et al. AGS67E, an Anti-CD37 Monomethyl Auristatin E Antibody-Drug Conjugate as a Potential Therapeutic for B/T-Cell Malignancies and AML: A New Role for CD37 in AML. Mol Cancer Ther. 2015; 14(7):1650-1660

26. Repetto-Llamazares AHV, Larsen RH, Patzke S, et al. Targeted Cancer Therapy with a Novel Anti-CD37 Beta-Particle Emitting Radioimmunoconjugate for Treatment of Non-Hodgkin Lymphoma. PLoS One. 2015;10(6):e0128816.

27. Zhao XB, Biswas S, Mone A, et al. Novel Anti-CD37 Small Modular Immunopharmaceutical (SMIP) Induces BCell-Specific, Caspase-Independent Apoptosis in Human CLL Cells. Blood. 2004;104(11):2515.

28. Burton DR, Pyati J, Koduri R, et al. Efficient neutralization of primary isolates of HIV-1 by a recombinant human monoclonal antibody. Science. 1994:266(5187):1024-1027.

29. Deckert. J. CD37-binding molecules and immunoconjugates thereof. WO 2011/112978A1.(2011).

30. Vink T, Oudshoorn-Dickmann M, Roza M Reitsma J-J, de Jong RN. A simple, robust and highly efficient transient expression system for producing antibodies. Methods. 2014;65(1):5-10.

31. Cook EM, Lindorfer MA, van der Horst $\mathrm{H}$, et al. Antibodies That Efficiently Form Hexamers upon Antigen Binding Can Induce Complement-Dependent Cytotoxicity under Complement-Limiting
Conditions. J Immunol. 2016;197(5):17621775

32. Cragg MS, Morgan SM, Chan HTC, et al. Complement-mediated lysis by anti-CD20 $\mathrm{mAb}$ correlates with segregation into lipid rafts. Blood. 2003;101(3):1045-1052.

33. Chou T-C. Theoretical Basis, Experimental Design, and Computerized Simulation of Synergism and Antagonism in Drug Combination Studies. Pharmacol Rev. 2006;58(3):621-681.

34. Beckwith KA, Byrd JC, Muthusamy N. Tetraspanins as therapeutic targets in hematological malignancy: a concise review. Front Physiol. 2015;6:91.

35. Teo EC-y, Chew Y, Phipps C. A review of monoclonal antibody therapies in lymphoma. Crit Rev Oncol Hematol. 2016:97:72-84

36. Xu-Monette ZY, Li L, Byrd JC, et al Assessment of CD37 B-cell antigen and cell of origin significantly improves risk prediction in diffuse large B-cell lymphoma. Blood. 2016;128(26):3083-3100.

37. de Winde CM, Elfrink $S$, van Spriel AB Novel Insights into Membrane Targeting of B Cell Lymphoma. Trends Cancer. 2017;3(6):442-453

38. Hemler ME. Tetraspanin functions and associated microdomains. Nat Rev Mol Cell Biol. 2005;6(10):801-811.

39. Simons K, Sampaio JL. Membrane Organization and Lipid Rafts. Cold Spring Harb Perspect Biol. 2011;3(10):a004697.

40. Hicks SW, Lai KC, Gavrilescu LC, et al. The Antitumor Activity of IMGN529, a CD37Targeting Antibody-Drug Conjugate, Is Potentiated by Rituximab in Non-Hodgkin Lymphoma Models. Neoplasia (New York, NY). 2017:19(9):661-671

41. Repetto-Llamazares AHV, Malenge MM O'Shea A, et al. Combination of (177) Lulilotomab with rituximab significantly improves the therapeutic outcome in preclinical models of non-Hodgkin's lymphoma. Eur J Haematol. 2018;101(4):522-531.

42. Dienstmann R, Patnaik A, GarciaCarbonero R, et al. Safety and Activity of the First-in-Class Sym004 Anti-EGFR Antibody Mixture in Patients with Refractory Colorectal Cancer. Cancer Discov. 2015;5(6):598-609.

43. Jacobsen HJ, Poulsen TT, Dahlman A, et al. Pan-HER, an Antibody Mixture Simultaneously Targeting EGFR, HER2, and HER3, Effectively Overcomes Tumor Heterogeneity and Plasticity. Clin Cancer Res. 2015;21(18):4110-4122. 